\title{
Assembly and Maintenance of Full Scale NIF Amplifiers in the Amplifier Module Prototype Laboratory (AMPLAB)
}

\author{
J. A. Horvath
}

This paper was prepared for submittal to the

Third Annual International Conference on Solid State Lasers for

Application (SSLA) to Inertial Confinement Fusion (ICF)

Monterey, California

June 7-12, 1998

July 16, 1998

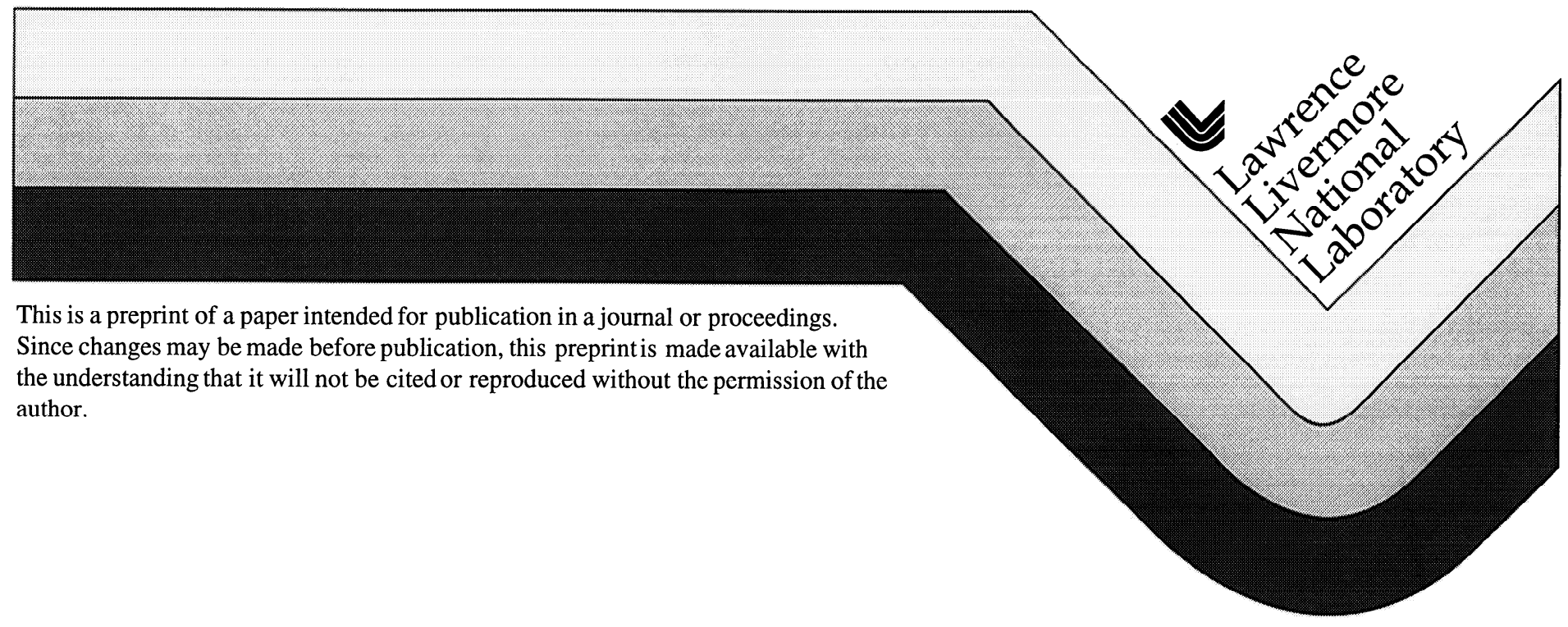




\section{DISCLAIMER}

This document was prepared as an account of work sponsored by an agency of the United States Government. Neither the United States Government nor the University of California nor any of their employees, makes any warranty, express or implied, or assumes any legal liability or responsibility for the accuracy, completeness, or usefulness of any information, apparatus, product, or process disclosed, or represents that its use would not infringe privately owned rights. Reference herein to any specific commercial product, process, or service by trade name, trademark, manufacturer, or otherwise, does not necessarily constitute or imply its endorsement, recommendation, or favoring by the United States Government or the University of California. The views and opinions of authors expressed herein do not necessarily state or reflect those of the United States Government or the University of California, and shall not be used for advertising or product endorsement purposes. 


\title{
Assembly and Maintenance of Full Scale NIF Amplifiers in the Amplifier Module Prototype Laboratory (AMPLAB)
}

\author{
J. A. Horvath Lawrence \\ Lawrence Livermore National Laboratory, MS L490 \\ Livermore, California 94550 USA
}

\begin{abstract}
Mechanical assembly and maintenance of the prototype National Ignition Facility amplifiers in the Amplifier Module Prototype Laboratory (AMPLAB) at Lawrence Livermore National Laboratory requires specialized equipment designed to manipulate large and delicate amplifier components in a safe and clean manner. Observations made during the operation of this assembly and maintenance equipment in AMPLAB provide design guidance for similar tools being built for the National Ignition Facility. Fixtures used for amplifier frame installation, laser slab and flashlamp cassette assembly, transport, and installation, and in-situ blastshield exchange are presented. Examples include a vacuum slab gripper, slab handling clean crane, slab cassette assembly fixture, sealed transport vehicle for slab cassette movement between the cleanroom and amplifier, slab cassette transfer fixture between the cleanroom and transport vehicle, and equipment needed for frame assembly unit, blastshield, and flashlamp cassette installation and removal. The use of these tools for amplifier assembly, system reconfiguration, reflector replacement, and recovery from an abnormal occurrence such as a flashlamp explosion is described. Observations are made on the design and operation of these tools and their contribution to the final design of their NIF counterparts.
\end{abstract}

\section{KEYWORDS}

AMPLAB, amplifier, frame, FAU, LRU, cassette, flashlamp, slab, vehicle, SMIF.

\section{INTRODUCTION}

The Amplifier Module Prototype Laboratory (AMPLAB) was constructed at Lawrence Livermore National Laboratory for verification and testing of full size National Ignition Facility (NIF) amplifiers ${ }^{1}$ and all equipment needed for their assembly and maintenance. The physical arrangement of amplifier and diagnostic system hardware AMPLAB (fig. 1) permits testing of amplifier line replaceable units (LRU) assembly tools, LRU installation vehicle, optical component handling equipment, and procedures for safe and clean amplifier operation. The January, 1997 AMPLAB dedication ceremony (fig.2) celebrated the joint French and American efforts that this facility represents.

The AMPLAB prototype amplifier can be reconfigured by exchanging LRUs, thus providing a

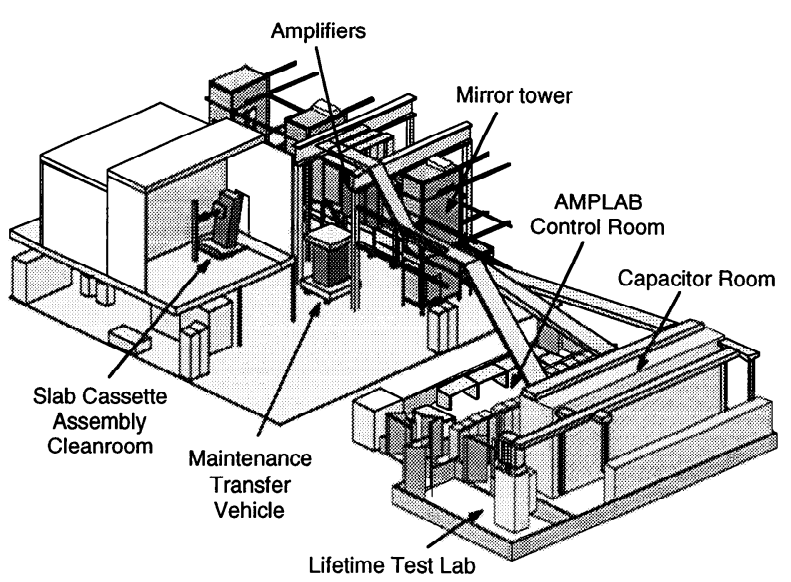

Figure 1. AMPLAB contains all systems required to verify assembly, maintenance, and clean operation of full

Work performed under the auspices of the U.S. Department of Energy by Lawrence Livermore National Laboratory under Contract No. W-7405-Eng-48 
means for varying parameters for the characterization of amplifier optical ${ }^{2}$ and thermal performance and for refining amplifier performance models. The prototype amplifiers in AMPLAB are elevated to allow a prototype sealed maintenance vehicle to move beneath the amplifier (fig. 3).

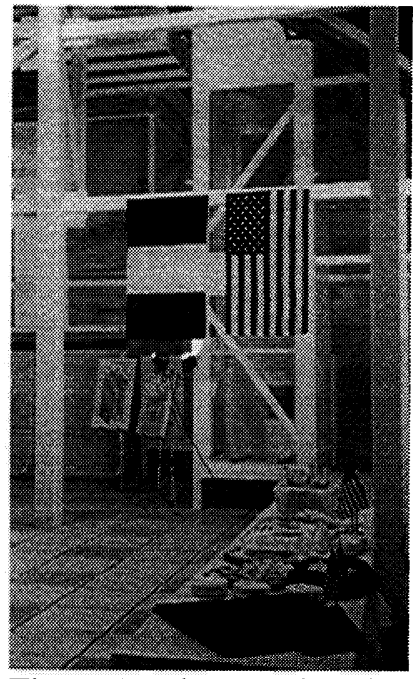

Figure 2. The French and American AMPLAB dedication was celebrated in January of 1997.

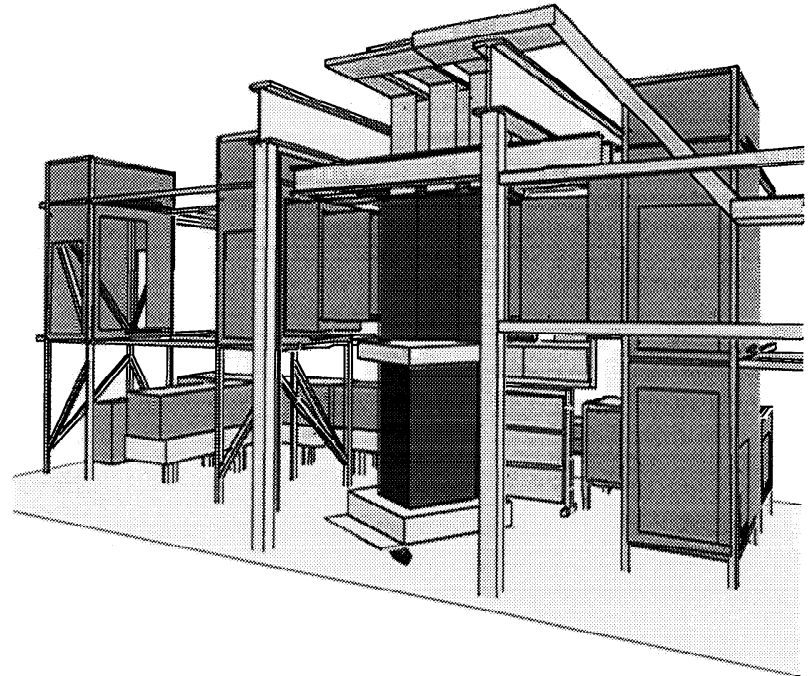

Figure 3. The prototype MTV illustrated beneath the elevated amplifiers is capable of reconfiguring the test amplifier for a variety of experiments.

Lifetime testing of flashlamps and other amplifier components is conducted in an area adjacent to the AMPLAB control room. The flashlamp and blastshield lifetime test fixture (fig. 4) shares the capacitor bank with the AMPLAB amplifiers by use of interlocked load selection switches. This fixture can fire 40 flashlamps every five minutes for 24 hours per day. It is used for flashlamp vendor qualification tests, flashlamp lifetime tests, and blastshield assembly exposure tests.

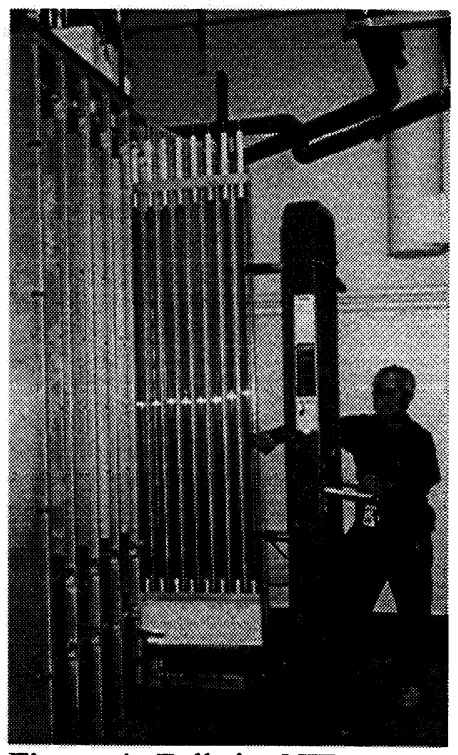

Figure 4. Full size NIF flashlamps are fired in 5-minute intervals for lifetime verification.

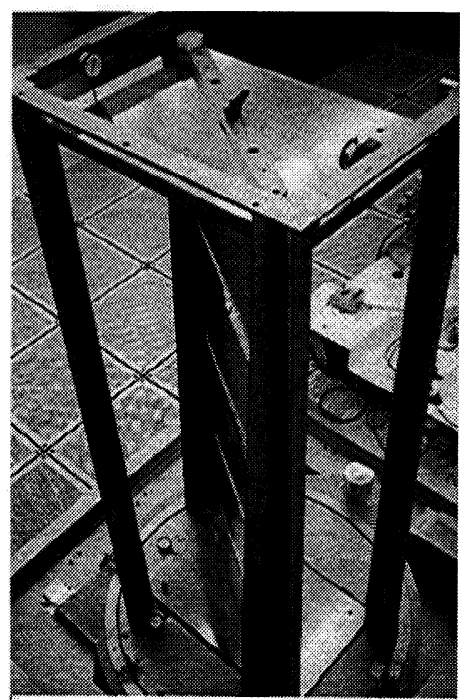

Figure 5. Slab cassette insertion repeatability was measured in the cleanroom transfer fixture.

A class- 100 cleanroom that is raised to the same height above ground as the amplifiers is configured to test slab cassette assembly, transfer, slab handling equipment. The slab cassette transfer fixture in the assembly cleanroom 
provided access and visibility for test such as the cassette transfer repeatability test (fig. 5). The ability to directly observe the transfer of a slab cassette to and from a transfer vehicle was helpful in developing an understanding of the interface between the cassette and the amplifier frame during insertion and removal operations. The elevated cleanroom and elevated amplifiers in AMPLAB permit full size tests of a slab cassette LRU maintenance vehicle. LRU components are cleaned at a remote location and brought to AMPLAB for final assembly. AMPLAB is used to develop procedures and tools for the clean assembly and transfer of components such as laser slabs, blastshields, and flashlamp cassette LRUs for NIF. The successful testing of the amplifier mechanical equipment described here was instrumental in the implementation of over 40 different types of LRUs in the NIF laser system. AMPLAB is configured such that optical performance, thermal recovery, and operational cleanliness can be measured. A test firing of the AMPLAB amplifiers (fig. 6) can provide amplifier gain, wavefront, thermal recovery, and cleanliness data ${ }^{3}$ simultaneously. The use of cassettes and specialized tools for their manipulation facilitates rapid changes of amplifier components or configurations by exchanging of LRUs.

\section{Amplifier Mechanical Design}

The NIF amplifiers are composed of LRUs installed into a permanently mounted metal frame called a frame assembly unit (FAU). The AMPLAB FAUs were designed as open frames with removable side panels (fig. 7). The removable access panels permit internal inspections of the flashlamp cavity and pump cavity during prototype testing. The NIF design will permit access only from the bottom due to the close proximity of neighboring amplifiers and the arrangement of structural supports. Assembly and maintenance of bottom-loading amplifiers is accomplished by the manipulation of cassette LRUs that contain laser glass slabs or flashlamps and associated silver-plated reflectors. Components that require periodic maintenance can thus be replaced without delaying subsequent laser system shots.

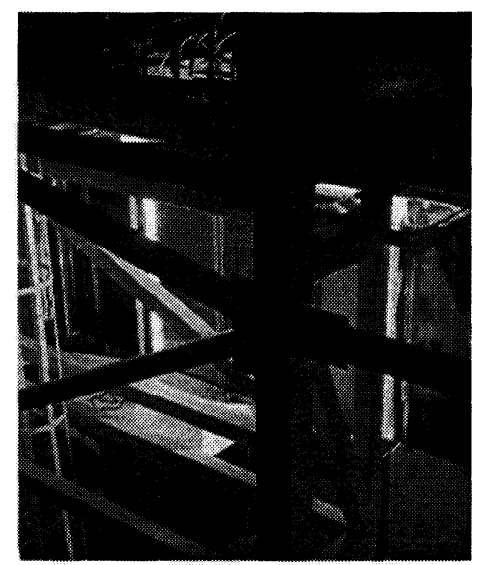

Figure 6. Internal flashlamps illuminate amplifier insulators during an AMPLAB shot.

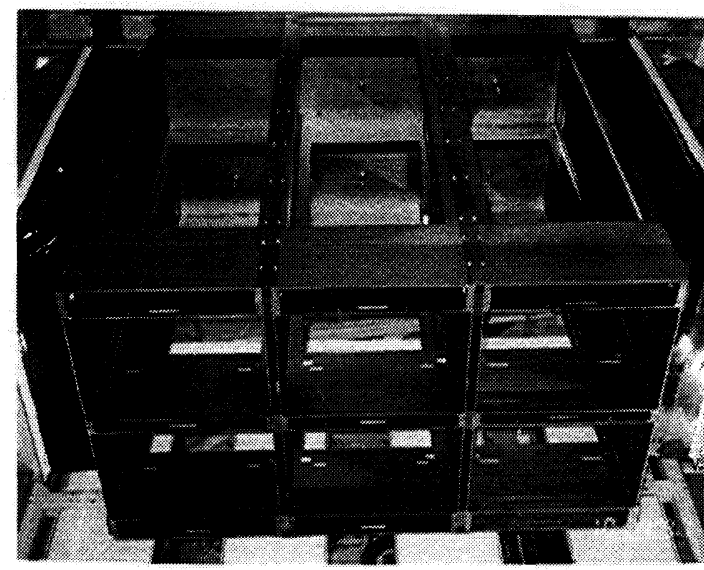

Figure 7. Empty FAUs viewed from below have no side panels, blastshields, flashlamp cassettes, or slab cassettes installed.

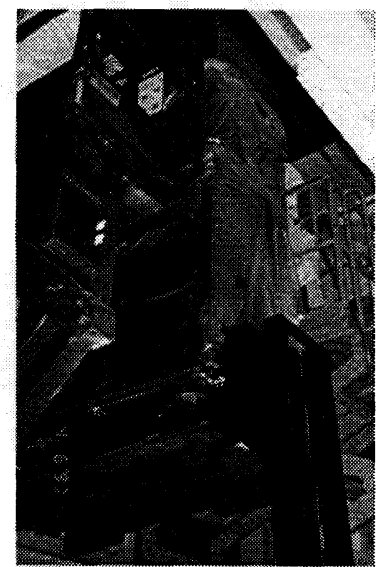

Figure 8. The AMPLAB FAUs are positioned using a six DOF platform.

The amplifier FAU supports the amplifier slab cassette LRUs, flashlamp cassette LRUs, blastshields, flashlamp electrical connectors, and bottom covers in their required locations. The AMPLAB FAUs are installed and removed using an electric universal lifting vehicle (ULV) and a six-degree-of-freedom FAU installation fixture attached to the ULV forks as shown in Figure 8. The ULV is an electric forklift that fits beneath the amplifier. The ULV has adequate vertical travel to install FAUs, flashlamp cassette LRUs, and blastshields by mounting the appropriate interface fixture to the forks. This six DOF positioning interface was used in AMPLAB for the precise manipulation of FAUs and also for blastshield manipulation. 


\section{Blastshield Replacement}

Blastshields separate the flashlamp cavity from the laser slab pump cavity. The blastshields in the AMPLAB amplifier are designed to be replaceable in-situ. Blastshield replacements in AMPLAB are accomplished using a blastshield fixture mounted to the ULV. This blastshield installation fixture (fig. 9, 10,11) includes miniature infrared video cameras to assist the vehicle operator in manipulating the blastshield inside the amplifier. The ULV supports the installation fixture and provides coarse motion control. Fine movement control is achieved using the six-DOF interface platform, which is part of the installation fixture. It employs an array of jacks and rollers for lateral and vertical motion.

Blastshield glass is cleaned in a facility outside of AMPLAB. A sol gel antireflective coating is applied in a second facility located in a different building. The blastshield glass is transported back to AMPLAB where metal frames are glued in place. The assembled blastshields are then moved to the amplifier where an insertion fixture is used to perform

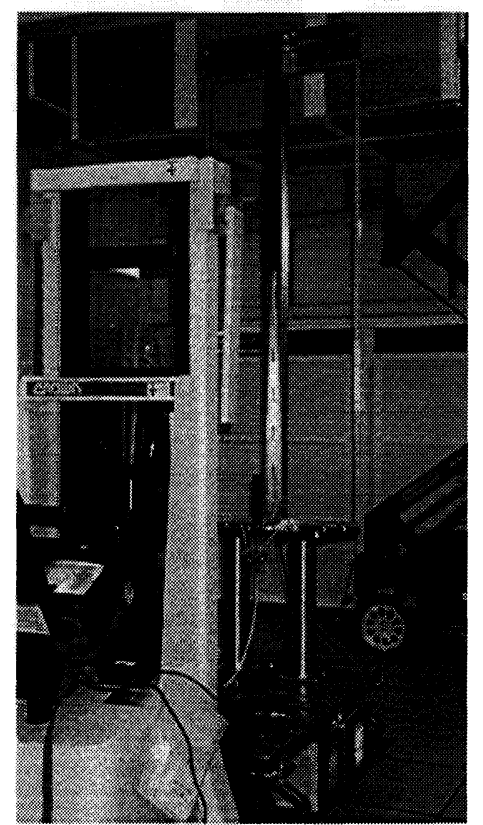

Figure 9. Blastshields are installed and removed using a tool equipped with video cameras.

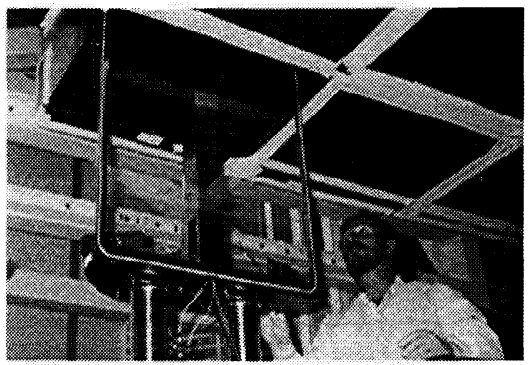

Figure 10. A blastshield is being installed using the positioning tool.

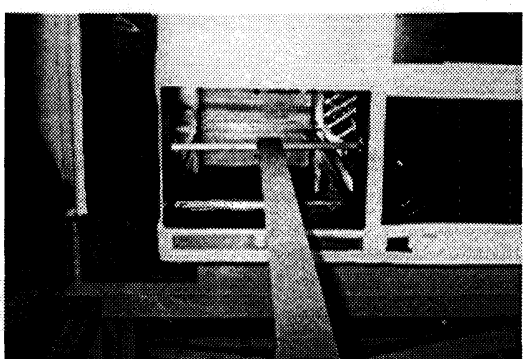

Figure 11. This view is from below the amplifier looking upward.

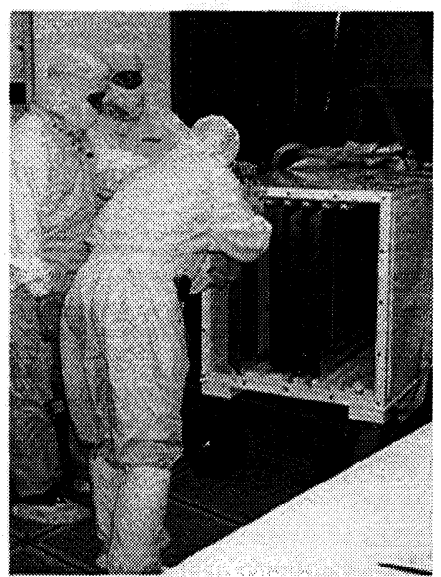

Figure 12. The blastshield transfer box is used for ammonia curing of sol gel coated glass and for clean storage of assembled units.

the blastshield exchange in the amplifier. A blastshield transport and storage system was built to perform protect the untempered glass from damage or contamination. The clean, sealed containers are used for transit and to provide the sealed container for ammonia hardening of the sol gel coatings. The internal mounting points support either bare glass or the larger framed blastshields (fig. 12). These containers are also used to protect spare blastshields from damage or contamination.

\section{Slab Cassette and Flashlamp Cassette LRUs}

The NIF amplifier design uses sealed blastshields to isolate laser glass in the pump cavity from flashlamps in the actively cooled flashlamp cavity. The 768 slab cassette LRUs and 1,152 flashlamp cassette LRUs will be loaded into the NIF amplifier from below using sealed clean enclosures called canisters carried by automated transporter vehicles. The amplifier design shown in Figure 13 is compact in order to increase efficiency, resulting in close tolerances between LRUs and the FAU, and compact cassette geometry. Slab cassettes contain four laser glass slabs stacked on each other and separated by corrugated metal springs to minimize vertical height. Flashlamp cassettes include shaped reflectors that enhance gain uniformity across the aperture of the laser. 
The task of transferring assembled slab cassette LRUs between the AMPLAB optical assembly cleanroom and the prototype amplifier is performed by a maintenance transfer vehicle (MTV). Testing of the bottom-loading amplifier concept was first performed in AMPLAB using a prototype MTV in June of 1997. The construction and maintenance of full size NIF amplifiers in AMPLAB required development and implementation of a fully functional MTV in parallel with NIF amplifier component development. The MTV, shown in operation in Figure 14 and Figure 15 required fully functioning alignment, docking, cover removal, LRU lock actuation, clean transfer, and control systems. The MTV is based on isolation technology, sometimes referred to as "standard mechanical interface", or SMIF technology. The SMIF concept involves the docking of a sealed clean environment to another sealed clean environment for the purpose of transferring a clean part through an uncontrolled environment, thereby isolating the part from contamination originating in the surroundings. Docking locations for the AMPLAB MTV include the underside of the elevated cleanroom and six

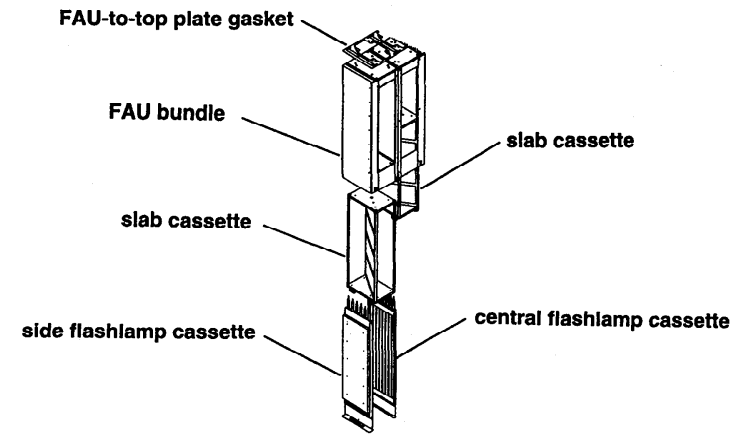

Figure 13. Removable slab cassettes and flashlamp cassettes require clean, sealed maintenance vehicles.

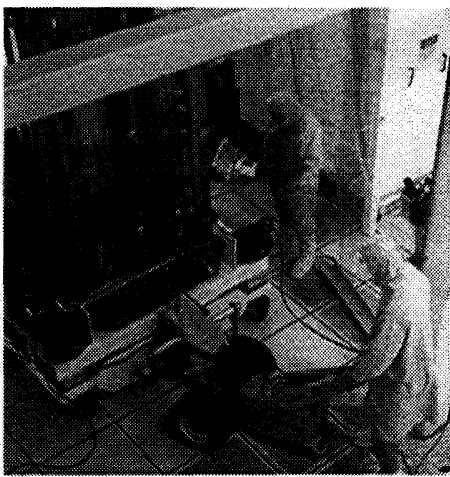

Figure 14. A tow tractor is used to push the MTV into position beneath the amplifier.

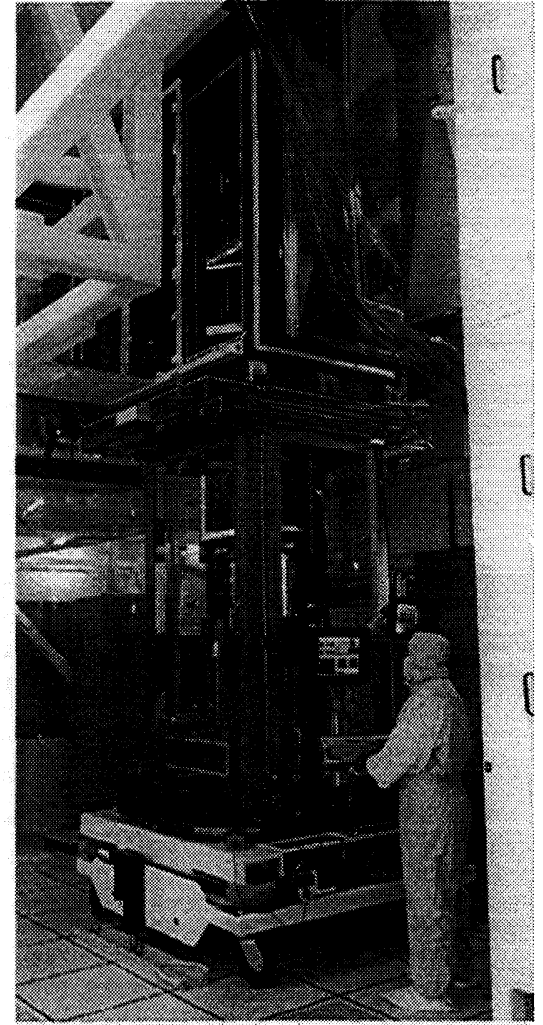

Figure 15. This slab cassette transfer vehicle was used for system development and AMPLAB operation.

amplifier FAU locations. The AMPLAB MTV has been used for more than 100 slab cassette transfers since it began operation in June of 1997. The NIF laser system will employ a fleet of larger LRU transport vehicles that contain key elements of the AMPLAB MTV with modifications based on test results and the need for vehicle component commonality.

AMPLAB slab cassette LRUs are assembled in an elevated class 100 cleanroom using an assembly fixture to manipulate the slab cassette frame during laser slab insertion or removal. The AMPLAB slab cassette assembly cleanroom shown in Figure 1 is elevated to the same height as the amplifiers to allow the MTV to dock below the cassette assembly fixture. The fixture rotates and tilts to optimally position the cassette for various assembly and transfer operations. The fixture is moved to the vertical position and rotated square with the docking port opening in the cleanroom floor for transfer of the finished cassette to the MTV or for receiving a cassette from the MTV. This same concept will be used in the Optics Assembly Building (OAB) for the assembly and transfer of 967 slab cassette LRUs for NIF. 
The laser slabs are brought to the assembly cleanroom and positioned for acquisition by the vacuum gripper using a clean slab carrier (fig. 16). The slab carrier supports laser slabs in the same frames used to support them during washing. The amplifier slab is held by a vacuum gripper that is manipulated using a clean crane designed and built for AMPLAB. It is composed of a slab cassette assembly fixture for positioning the cassette frame for optimum installation of laser slabs, a vacuum gripper for inserting the slabs without human handling, and a clean crane for manipulating the vacuum gripper (fig 17). The clean crane is also used for moving empty slab cassette frames into the assembly fixture. The AMPLAB prototype uses the assembly fixture for positioning the slab cassette for transfer to the MTV. The fixture is locked in a vertical position square with the docking port in the cleanroom floor for this operation. During cassette assembly the fixture is tilted back and rotated as required for slab insertion and slab mask installation (fig. 18). This same crane and gripper design will be used for laser slab handling in the NIF OAB.

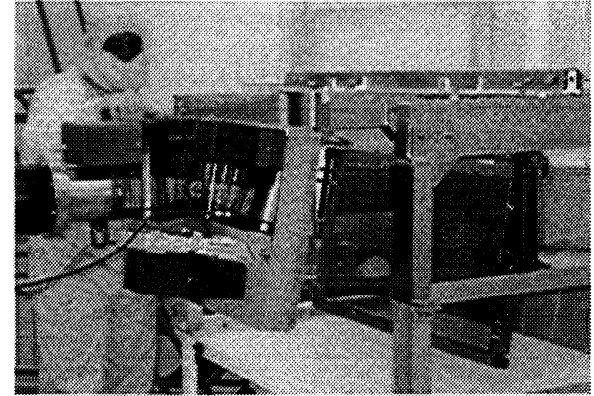

Figure 16. A laser slab in a washing frame is about to be acquired by a vacuum slab gripper during a slab cassette assembly in the AMPLAB Class 100 cleanroom.

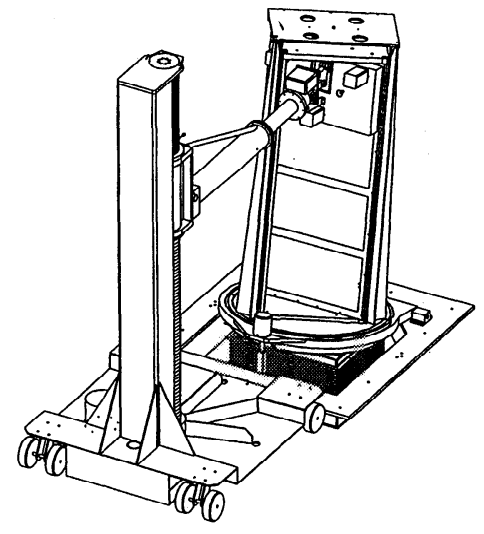

Figure 17. The clean crane, vacuum gripper, and assembly and transfer fixture are similar to those planned for NIF.

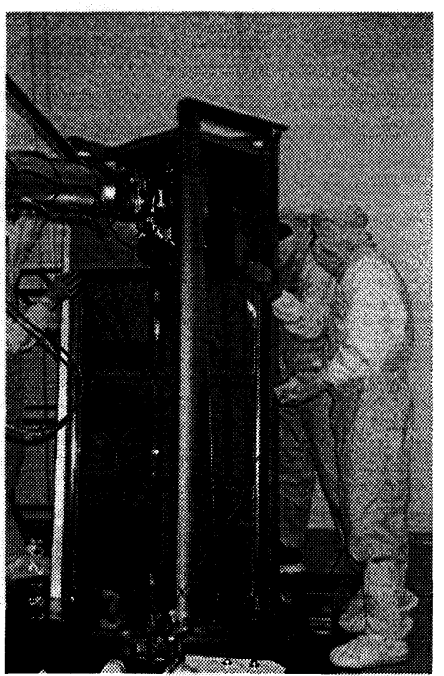

Figure 18. The vacuum gripper permits slab insertion into the cassette frame.

AMPLAB flashlamp cassette LRUs are assembled in a cleanroom and transferred to the main floor of AMPLAB for insertion into the amplifier. They are supported and positioned by the fixture shown in Figure 19. Flashlamp cassettes are not lifted manually due to their weight and the danger associated with a broken flashlamp. The flashlamp cassettes are inserted into the AMPLAB amplifier using a fixture attached to the ULV described earlier. This process is shown in

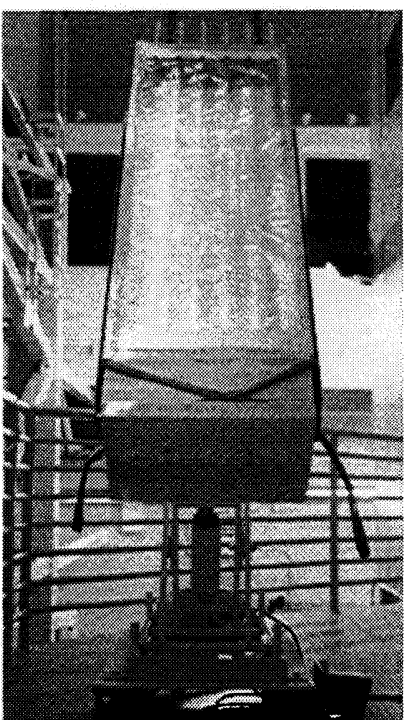

Figure 19. Positioners are used to manipulate assembled flashlamp cassettes.

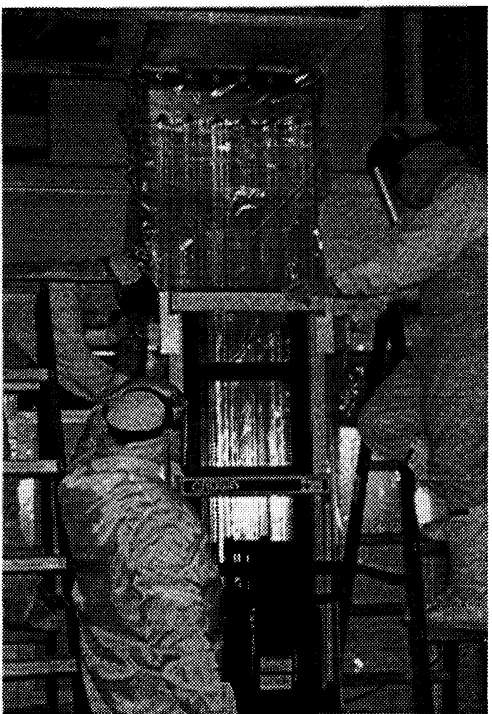

Figure 20. Insertion and removal of AMPLAB flashlamp cassettes was accomplished using a modified lift vehicle and sealed wrapping. 
Figure 20. A sealed flashlamp cassette transport vehicle was not built for AMPLAB since the cleanliness requirements for the amplifier flashlamp cavity could be met using a crossflow class 100 clean zone beneath the amplifiers. The flashlamp cassettes were wrapped in cleanroom plastic and positioned beneath the flashlamp cavity. The cleanroom plastic was peeled back as the cassettes were inserted.

The use of flashlamp vendor preliminary prototype flashlamps combined with early pulsed power system problems led to four flashlamp explosions inside the prototype amplifier during the first year of AMPLAB operation. The flashlamp cassettes and associated broken quartz envelope shards were successfully extracted on each occasion using the insertion fixture combined with a glass collection bag positioned below the flashlamp cavity opening. These experiences provided valuable observations regarding recovery from similar events when they occur in the NIF amplifiers.

\section{CONTRIBUTIONS TO NIF DESIGNS}

The movement of clean laser slabs into the NIF optical assembly cleanroom will be accomplished using a more refined version of the AMPLAB system. The slabs will still be carried on their washing frames, however the NIF washing frame will be compatible with a robotic washing system. A transfer box with removable sides will carry a pair of slabs and present them to the vacuum slab gripper in a manner similar to the AMPLAB approach.

Slab cassette and flashlamp cassette LRU for NIF will be done by sealed canisters carried from one location to another by transport vehicles (fig. 21). The use of specialized canisters carried by a universal transport vehicle reduced the complexity of the NIF hardware. The slab cassette and flashlamp cassette canisters incorporate improved versions of the AMPLAB cover removal system (fig. 22). The alignment and docking are achieved using robust kinematic mounts rather than active alignment positioning. Insertion clearances for amplifier LRUs have been increased based on AMPLAB mechanical assembly experience.

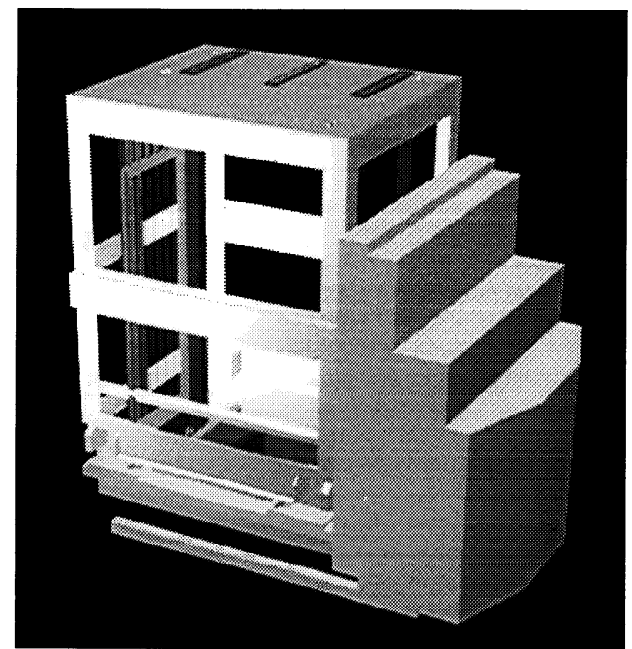

Figure 21. The NIF canister and transporter uses standardized parts for economv.

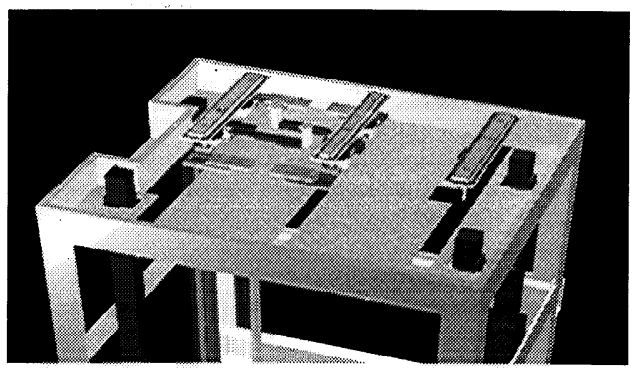

Figure 22. The NIF canister cover remover design was influenced by AMPLAB vehicle system tests.

NIF FAUs will be assembled with blastshields preinstalled. However NIF amplifier blastshields are designed to be line-replaceable in-situ if the need should arise. They are not considered to be LRUs in the NIF baseline definition, therefore no canister will be built for their installation. A version of the AMPLAB blastshield transfer and storage system will be used for NIF blastshield production, transfer, and clean storage.

Improved versions of the AMPLAB vacuum slab gripper and cleanroom crane will be used for the assembly of NIF slab cassettes. Two workstations will be built in order to meet the production rate called for by the NIF LRU installation plan (fig. 23). The AMPLAB slab cassette assembly and transfer fixture will become two separate fixtures in the NIF assembly cleanroom. The upper portion of the fixture will be used to support the slab cassette during all assembly, 
inspection, and transfer operations within the cleanroom. A tilting and rotating support base will be used at four locations in the cleanroom to position the transfer frames during various phases of cassette assembly. A stationary attachment point will be provided at the cleanroom floor opening where vehicle docking will occur. This attachment point fixes the cassette position for transfer to the canister that will be docked below the floor.

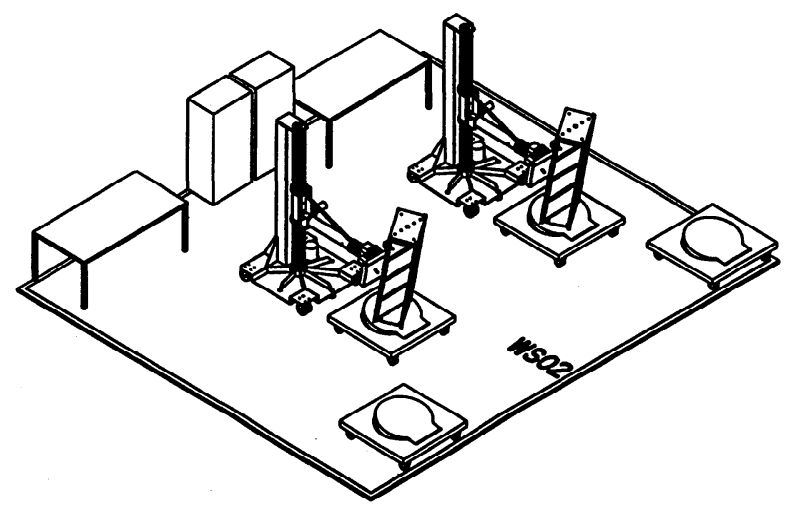

Figure 23. The NIF optical assembly facility will use improved versions of the AMPLAB cleanroom crane, vacuum gripper, and cassette assembly fixture.

Cleanliness measurements made on the AMPLAB prototype hardware during all phases of its installation and operation have contributed to the specification of required cleanliness levels as well as the development of verification methods for NIF. Procedures for clean assembly and transfer of amplifier LRUs written for AMPLAB operations form the basis for similar NIF procedures. This includes the specification of cleanroom garments, cleaning materials, isolation methods, and access procedures. Finally, the maintenance and operation of the complex AMPLAB hardware configuration has trained a core team of experienced technical leaders who will be responsible for the training of a much larger NIF cleanroom staff.

\section{ACKNOWLEDGEMENTS}

The author wishes to thank R. Akusis, T. Alger, W. Davis, A. Erlandson, J. Fisher, E. Hajdena, and J. Hall. T. Lee, R. McCracken, E. Moor, L. Morris, B. Pedrotti, S. Rodriguez, D. Silva, D. Swort, J. Trent (LLNL), T. Adjadj, J. Beullier, JC Fornerod, J-L Guinet, X. Maille, P. Manach, S. Seznec (CEL-V) and P. Bosch (SICN) for their participation in the design, fabrication, installation, and operation of the AMPLAB amplifier hardware assembly and maintenance system.

\section{REFERENCES}

1. J. Horvath, "NIF / LMJ Prototype Amplifier Mechanical Design," Second Annual International Conference on Solid State Lasers for Application to Inertial Confinement Fusion, Paris, France, October 1996.

2. L. Zapata, R. McCracken, J. Horvath, A. Erlandson (LLNL), E. Grebot, J.-L. Guenet, S. Seznec (CEL-V), "Large Aperture Diagnostic System for Gain and Wavefront Measurements on NIF/LMJ Amplifiers," Second Annual International Conference on Solid State Lasers for Application to Inertial Confinement Fusion, Paris, France, October 1996.

3. I.F. Stowers, J.A. Horvath, J.A. Menapace, "Achieving and Maintaining Cleanliness in NIF Amplifiers", Third Annual International Conference on Solid State Lasers for Application to Inertial Confinement Fusion, Monterey, California, USA, June 1998. 